\section{Seasonal variation of digestible energy requirements of mature donkeys in the UK}

\author{
Stephanie J. Wood', David G. Smith² and Catherine J. Morris ${ }^{3}$
}

Centre for Tropical Veterinary Medicine, University of Edinburgh' ${ }^{1}$, School of Biological Sciences, University of Aberdeen ${ }^{2}$ and c Bransby Home of Rest for Horses $^{3}$

\section{Introduction}

Acute and chronic overfeeding of equines is a major cause of poor welfare in the United Kingdom, resulting in sudden fatalities caused by diseases like hyperlipaemia (Fowler 1995), or premature euthanasia due to conditions such as laminitis and colic (Crane 2000). Donkeys are particularly susceptible to this abuse as they are mostly kept as companion animals with few, if any, work demands. The problem of overfeeding donkeys is further exacerbated by the lack of information distinguishing their nutritional requirements from those of horses and ponies. This absence of specific feeding recommendations forces owners and professionals to draw upon feeding guidelines already developed for horses. Taylor (2000) suggests donkey feeding requirements on a body weight basis are 0.75 of those published for horses. However, it is not known if these recommendations over estimate nutritional demand and subsequently add to the problem of over weight donkeys.

The formation of feeding recommendations begins with the calculation of energy requirements for maintenance, as this is the value to which other nutrients are related. A number of studies have been carried out into the energy requirements of donkeys, although their focus has primarily been on the energy demands of working donkeys transporting loads over various distances and terrain (Yousef and Dill 1969, Pearson et al. 2001, Ram et al. 2004). Values for dry matter intake (DMI) and digestible energy (DE) intake by donkeys at rest are quoted in a number of studies (Pearson and Merritt 1991, Cuddeford et al. 1995, Ram et al. 2004) however these studies only observed small numbers of animals over short periods of time. No study has been carried out to determine the DE requirements of donkeys for maintenance during the different seasons of the UK climate.

The aim of this study was to determine the maintenance digestible energy requirements of mature donkeys during summer and winter.

\section{Materials and methods}

The study took place between May 2003 and July 2004 at The Donkey Sanctuary, Sidmouth, Devon, UK. Two recording periods took place; the first between June and August 2003 and the second between December 2003 and February 2004. During recording periods the donkeys were housed in individual stables and received individual hay and barley straw rations in quantities that were adjusted to maintain body weight. An equilibrium period of 25 days was followed by a 5 day total faecal collection.

Animals

20 mature donkeys, 10 male, 10 female were selected for the study. 10 male $(159-217 \mathrm{~kg})$ and 8 female $(139-203 \mathrm{~kg})$ donkeys were used during the summer recording period and 7 male $(157-210 \mathrm{~kg})$ and 10 female $(133-200 \mathrm{~kg})$ donkeys during the winter period. The donkeys were weighed daily using a weigh bridge and the mean weekly body weight calculated.

Sample collection and laboratory analysis

Daily samples of food offered were taken for the last 7 days of each recording period. Samples of food refused and faeces were taken daily for each donkey for the last 12 and 5 days of each recording period, respectively, and pooled for each donkey. All samples were dried at $60^{\circ} \mathrm{C}$ to determine dry matter, and retained for laboratory analysis. Dried samples were ground using a hammer mill through a $1 \mathrm{~mm}$ screen. Food offered and faecal samples were analysed for neutral-detergent fibre (NDF), acid-detergent fibre (ADF), crude protein (CP), gross energy (GE) and organic matter $(O M)$ according to the methods reported by the Association of Official Chemists (1990). Daily dry matter, digestible energy and digestible crude protein intakes were calculated for each donkey.

\section{Results}

Body weight

Body weights remained stable throughout the study. Small losses occurred in the summer season whilst weight gain occurred in winter. The weight gain coincided with an increased hay ratio in the ration resulting in significantly greater DM and DE intakes $(P<0.001)$ (See table 1).

Table 2 Mean (+ s.e.) DM, DE and DCP intakes and dry matter digestibility (DMD) by males and female donkeys during summer and winter.

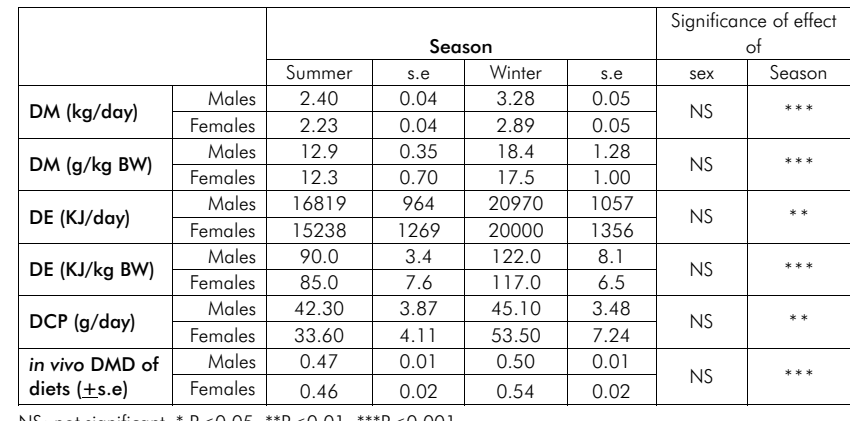

NS: not significant, ${ }^{*} P<0.05,{ }^{* * P}<0.01,{ }^{* * *} P<0.001$ 
Climate

Mean daily temperature during each recording period was $6^{\circ} \mathrm{C}$ and $20^{\circ} \mathrm{C}$ for summer and winter, respectively.

Diet composition, digestibility and intake

Diet composition is shown in table 2. The hay and straw fed in summer contained higher GE, NDF and ADF levels than those fed in winter. These higher NDF and ADF levels are reflected in the low DMl and DMD during the summer. CP levels for the hay fed in both seasons and the straw fed in winter are lower than those of published values (McDonald et al. 1995) and reflect low quality forage.

Table 1 Composition and energy density of diets offered $(\mathrm{g} / \mathrm{kg}$ DM unless otherwise stated).

\begin{tabular}{|c|c|c|c|}
\hline & & \multicolumn{2}{|c|}{ Season } \\
\hline & & Summer & Winter \\
\hline \multirow[t]{6}{*}{ Hay } & $\mathrm{DM}(\mathrm{g} / \mathrm{kg})$ & 920.6 & 901.8 \\
\hline & GE $(\mathrm{kJ} / \mathrm{kg} \mathrm{DM})$ & 15500 & 14900 \\
\hline & OM & 963.6 & 971.5 \\
\hline & $\mathrm{CP}$ & 52.8 & 44.0 \\
\hline & NDF & 774.9 & 648.7 \\
\hline & ADF & 401.1 & 370.7 \\
\hline \multirow[t]{6}{*}{ Straw } & $\mathrm{DM}(\mathrm{g} / \mathrm{kg})$ & 925.3 & 919.0 \\
\hline & GE (kJ/kg DM) & 16100 & 15300 \\
\hline & OM & 978.8 & 979.1 \\
\hline & $\mathrm{CP}$ & 51.7 & 32.6 \\
\hline & NDF & 879.3 & 846.5 \\
\hline & ADF & 549.2 & 493.1 \\
\hline \multicolumn{2}{|c|}{$\%$ Straw in ration } & 75 & 30 \\
\hline \multicolumn{2}{|c|}{$\%$ Hay in ration } & 25 & 70 \\
\hline \multicolumn{2}{|c|}{ Energy content of rations (kJ DE/kg DM) } & 6900 & 6700 \\
\hline
\end{tabular}

Daily DM, DE and DCP intakes are shown in table 2. Sex had no significant effect on any results obtained $(P>0.05)$. The increased hay: straw ratio in the winter ration resulted in a significant $(\mathrm{P}<0.01)$ increase in DMD and is reflected by the increase in DM (g/ $\mathrm{kg} \mathrm{BW)} \mathrm{and} \mathrm{DE} \mathrm{(} \mathrm{kJ} \mathrm{DE} / \mathrm{kg} \mathrm{BW)} \mathrm{intakes}$ during the winter $(P<0.001)$. The largest increase was seen in DE intake despite the lower energy value of the winter diet. Digestible crude protein (DCP) intakes were also significantly $(P<0.01)$ higher in winter.

\section{Discussion}

The lack of importance, socially in developing countries and economically in countries such as the UK, has resulted in only limited amounts of research into the donkey compared to that into the horse. The absence of feeding recommendations specific to donkeys results in them being fed as small horses. However, recent studies comparing the digestive efficiency of donkeys to that of other domestic equines have shown that donkeys are superior at digesting high fibre foods (Cuddeford et al. 1995, Pearson and Merritt 1991), and therefore probably require lower intakes.

Comparison of results from this study with NRC (1989) recommendations for ponies of the same body weight show the donkeys required considerably less daily DM, DE and DCP intakes for maintenance in both summer and winter.
DMI was 64 and $69 \%$ and DE intake was 54 and $74 \%$ of recommendations for summer and winter, respectively. The greater increase in DE intake during winter was achieved by increasing the hay ratio in the ration, therefore increasing the digestibility of the diet. CP intakes were also lower than NRC (1989) recommendations for both seasons despite low apparent digestibility. Comparison of these results with those from other studies is difficult due to the mixed ration fed here, although it is evident that the donkeys in this study had lower DM, DE and DCP intakes than those in previous studies (Pearson and Merritt 1991, Pearson et al. 2001, Ram et al. 2004).

\section{Conclusions}

These results show donkeys require less than 0.75 of horse rations that is currently recommended as a guide to feeding donkeys (Taylor 2000). It is also evident that a diet of low energy value is most suitable for feeding to donkeys to enable them to satisfy DMI requirements without consuming excess energy.

\section{References}

Association of Official Analytical Chemists (1990): Official methods of analysis of the Association of Analytical Chemists. 15th ed. Virginia, USA: Association of Analytical Chemists

Crane M. (2000): Medical. In: The professional handbook of the donkey. 3rd ed. London: Whittet Books, 19-36

Cuddeford D., Pearson R. A., Archibald R. F. and Muirhead R. H. (1995): Digestibility and gastro-intestinal transit time of diets containing different proportions of alfalfa and oat straw given to Thoroughbreds, Shetland ponies, Highland ponies and donkeys. Animal Science 61, 407-417

Fowler J. N. (1995): Common conditions of the donkey in temperate climates. The Veterinary Annual 35, 89-95

McDonald P., Edwards R. A., Greenhalgh J. F. D. and Morgan C. A. (1995): Animal nutrition. 5th ed. Essex, UK: Addison Wesley Longman Limited

National Research Council (1989): Nutrient requirements of horses. 5th ed. Washington D.C., USA: National Research Council

Pearson R. A., Archibald R. F. and Muirhead R. H. (2001): The effect of forage quality and level of feeding on digestibility and gastrointestinal transit time of oat straw and alfalfa given to ponies and donkeys. British Journal of Nutrition 85, 599-606

Pearson R. A. and Merritt J. B. (1991): Intake, digestibility and gastrointestinal transit time in resting donkeys and ponies and exercised donkeys given ad libitum hay and straw diets. Equine Vet J 23, 339-343

Ram J. J. et al. (2004): Nutritional requirements of adult donkeys (Equus asinus) during work and rest. Tropical Animal Health and Production 36, 407-412

Taylor F. (2000): Nutrition. In: The professional handbook of the donkey. 3rd ed. London: Whittet Books, 93-105

Yousef M. K. und Dill D. B. (1969): Resting energy metabolism and cardiorespiratory activity in the burro Equus asinus. Journal of Applied Physiology 27, 229-232

S. J. Wood

Centre for Tropical Veterinary Medicine

University of Edinburg

Easter Bush

Roslin, Midlothian, Edinburgh, EH25 9RG

s0240886@sms.ed.ac.uk 